\title{
The Disjunction Effect of Marine Bay Mouth to Zn
}

\section{Dongfang Yang ${ }^{1,2,4, a}$, Danfeng Yang ${ }^{3}$, Fengyou Wang ${ }^{1,2, b, c}$, Sixi Zhu ${ }^{1,2}$, and Mingzhong Long ${ }^{1,2}$}

${ }^{1}$ Research Center for Karst Wetland Ecology, Guizhou Minzu University, Guizhou Guiyang, Guizhou Guiyang, China

\author{
${ }^{2}$ College of Chemistry and Environmental Science, Guizhou Minzu University, Shanghai, 550025, \\ China \\ ${ }^{3}$ College of Information Science and Engineering, Fudan University, Shanghai, 200433, China \\ ${ }^{4}$ North China Sea Environmental Monitoring Center, SOA, Qingdao 266033, China \\ adfyang_dfyang@126.com; 'Corresponding author; ' ${ }^{\mathrm{c}}$ wangfy2001@yahoo.com.cn.
}

\begin{abstract}
Keywords: Marine bay mouth; Disjunction effect; Zn; Contents; Jiaozhou Bay
Abstract. Based on the investigation data on $\mathrm{Zn}$ in bottom waters in the bay mouth of Jiaozhou Bay in May, September and October in 1983, were analyzed the contents and distributions of $\mathrm{Zn}$. Results showed that $\mathrm{Zn}$ contents in bottom waters in May, September and October in the bay mouth of Jiaozhou Bay in 1983 were 1.24-120.66 $\mu \mathrm{g} \mathrm{L}^{-1}, 6.67-17.78 \mu \mathrm{g} \mathrm{L}^{-1}$ and $4.72-20.44 \mu \mathrm{g} \mathrm{L} \mathrm{L}^{-1}$, respectively. By means of the disjunction effect, no matter the substances were in the inner side or outside of the bay mouth in any marine bays, their contents would be decreasing once the waters were passing through the bay mouth. We called this phenomenon as 'Yang's phenomenon'. Zn contents in May, September and October in the outside of the bay mouth could be considered as high, low and moderate, while in the inner side of the bay mouth were all low, which were providing strong evidences for disjunction effect of marine bay mouth to $\mathrm{Zn}$.
\end{abstract}

\section{Introduction}

$\mathrm{Zn}$ is one of the essential elements to organisms, yet the excessive $\mathrm{Zn}$ contents are harmful to organisms. $\mathrm{Zn}$ is also one of the important materials widely used in industry and agriculture, and the Zn-containing waste water had caused many environmental problems including the deterioration of marine water quality [1-2]. Jiaozhou Bay is a semi-closed bay, which has been polluted by various pollutants including $\mathrm{Zn}$ due to the rapid development of industrialization and urbanization [1-2]. Based on investigation data on $\mathrm{Zn}$ in bottom waters in Jiaozhou Bay in 1983, eastern China, this paper analyzed the contents, distributions and the disjunction effect of $\mathrm{Zn}$, and provide basis for the research on the existence and migration of $\mathrm{Zn}$ in marine bay.

\section{Materials and method}

Jiaozhou Bay $\left(35^{\circ} 55^{\prime}-36^{\circ} 18^{\prime} \mathrm{N}, 120^{\circ} 04^{\prime}-120^{\circ} 23^{\prime} \mathrm{E}\right)$ is located in Shandong Province, eastern China, and is surrounding by cities of Qingdao, Jiaozhou and Jiaonan. The bay mouth is connected to the Yellow Sea in the south (Fig. 1). The size of the bay is $446 \mathrm{~km}^{2}$, yet the width of the bay mouth is only $2.5 \mathrm{~km}$. There were more than ten inflow rivers such as Dagu River, Haibo River, Licun River and Loushan River etc., most of which are seasonal rivers whose hydrological characteristics are mainly impacted by rainfall [3-4]. The data was provided by North China Sea Environmental Monitoring Center. The survey was conducted in May, September and October 1983. Surface and bottom water samples in five sampling sites (H34, H35, H36, H37 and H82) were collected and measured followed by National Specification for Marine Monitoring [5]. The seasons in study area in May, September and October could be considered as spring, summer and autumn, respectively. 


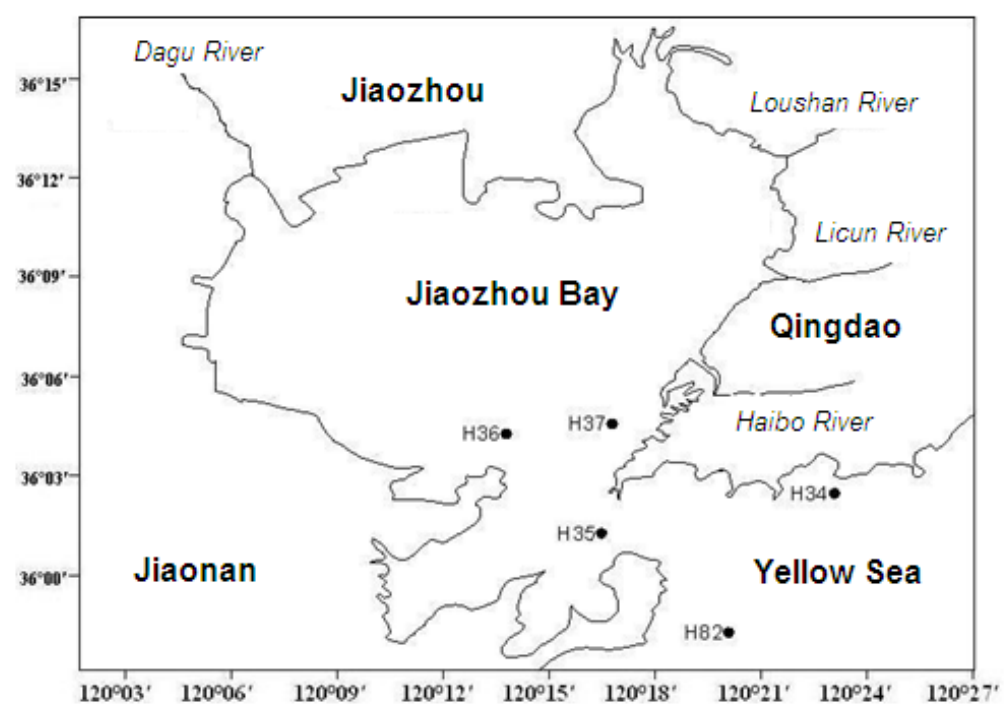

\section{Results and discussion}

Contents and pollution levels of Zn. Zn contents in bottom waters in May, September and October in the bay mouth of Jiaozhou Bay in 1983 were $1.24-120.66 \mu \mathrm{g} \mathrm{L}^{-1}, 6.67-17.78 \mu \mathrm{g} \mathrm{L} \mathrm{L}^{-1}$ and 4.72-20.44 $\mu \mathrm{g} \mathrm{L}^{-1}$, respectively (Table 1). In according to Guide line of $\mathrm{Zn}$ in National Standard of China for Seawater Quality (GB3097-1997) (Table 2), the pollution levels of Zn in May, September and October were Class I to IV, Class I and Class I to II, respectively (Table 1). The major sources of $\mathrm{Zn}$ in Jiaozhou Bay were marine current, overland runoff, stream flow, marine traffic and small peninsula. Once $\mathrm{Zn}$ was inputted to the bay, it was firstly arrived at the surface waters, and then was transferred to bottom waters via vertical water's effect [6]. In generally, the pollution levels of $\mathrm{Zn}$ in May, September and October could be considered as heavy pollution, moderate pollution and slight pollution, respectively. The reason was that there were different pollution sources of $\mathrm{Zn}$ in different seasons. The major sources of $\mathrm{Zn}$ in May was marine current whose source strength was very strong, and therefore $\mathrm{Zn}$ contents and pollution levels were relative high in May. The major sources in September and October were marine terminals and small peninsula in the bay mouth, whose source strengths were relative low, so $\mathrm{Zn}$ contents and pollution levels were relative low in September and October.

Table 1 Pollution level of $\mathrm{Zn}$ in May, September and October in Jiaozhou bay

\begin{tabular}{cccc}
\hline Time & May & September & October \\
\hline Content $/ \mu \mathrm{g} \mathrm{L}^{-1}$ & $1.24-120.66$ & $6.67-17.78$ & $4.72-24.44$ \\
Class & I, II, III, IV & I & I, II \\
\hline
\end{tabular}

Table 2 Guide line of Zn in National Standard of China for Seawater Quality (GB3097-1997)

\begin{tabular}{ccccc}
\hline Class & I & II & III & IV \\
\hline Guide line $/ \mu \mathrm{g} \mathrm{L}^{-1}$ & 20.00 & 50.00 & 100.00 & 500.00 \\
\hline
\end{tabular}

Horizontal distributions of Zn. Among the five sampling Sites, Site H36 and H37 were located in the inner side of the bay mouth, Site H35 was located in the middle of bay mouth, and Site H34 and H82 were located in the outside of the bay mouth. In May, a high value region was formed around Site H34 (120.66 $\left.\mu \mathrm{g} \mathrm{L}^{-1}\right)$ in the outside of the bay mouth with a series of different gradient parallel lines which were decreasing from the high value center to the bay mouth $\left(1.24 \mu \mathrm{g} \mathrm{L}^{-1}\right)$ along with the flow direction of the marine current (Fig. 2). In September, a relative high value region was also formed around Site H34 $\left(17.78 \mu \mathrm{g} \mathrm{L}^{-1}\right)$ in the outside of the bay mouth with a series of different gradient parallel lines which were decreasing from the high value center to the bay mouth $(6.67 \mu \mathrm{g}$ 
$\mathrm{L}^{-1}$ ) along with the flow direction of the marine current (Fig. 3). In September, a relative high value region was also formed around Site $\mathrm{H} 82\left(24.44 \mu \mathrm{g} \mathrm{L}{ }^{-1}\right)$ in the outside of the bay mouth with a series of different gradient parallel lines which were decreasing from the high value center to the bay mouth $\left(4.72 \mu \mathrm{g} \mathrm{L}^{-1}\right)$ along with the flow direction of the marine current (Fig. 4). The distributions of $\mathrm{Zn}$ contents in different seasons were showing that $\mathrm{Zn}$ contents were decreasing along with the flow direction of the marine current when were passing through the bay mouth.

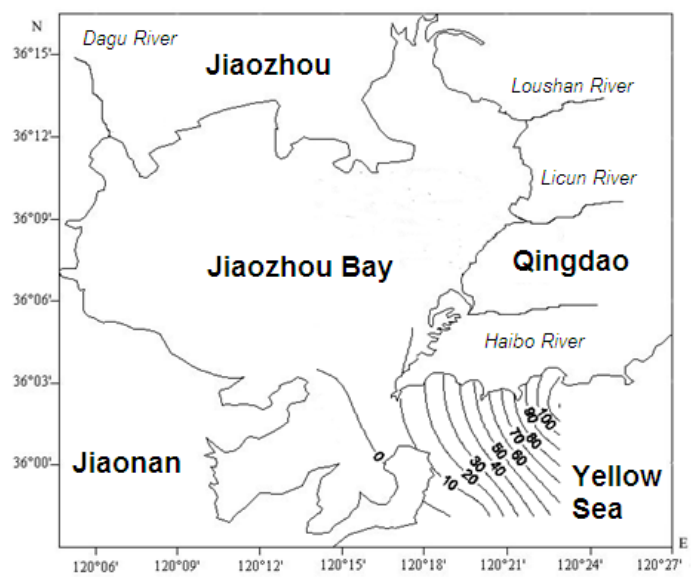

Fig. 2 Distributions of $\mathrm{Zn}$ in bottom waters in Jiaozhou Bay in May 1983/ $\mu \mathrm{g} \mathrm{L} \mathrm{L}^{-1}$

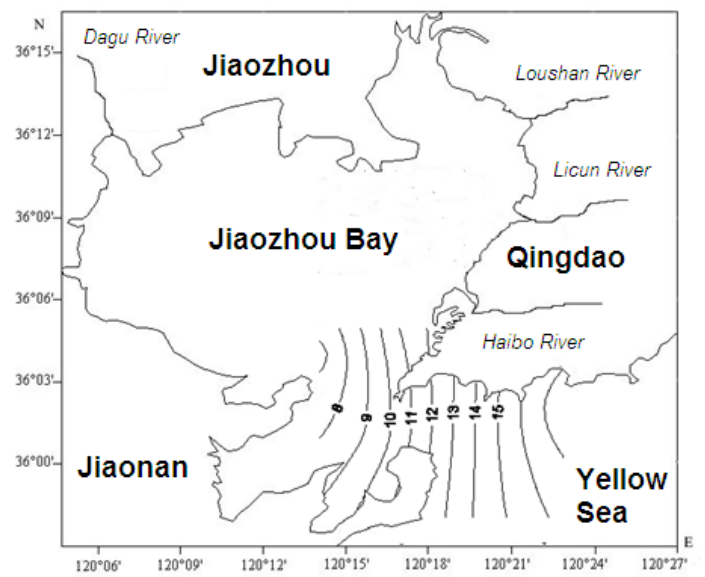

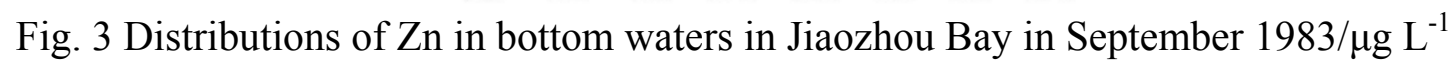

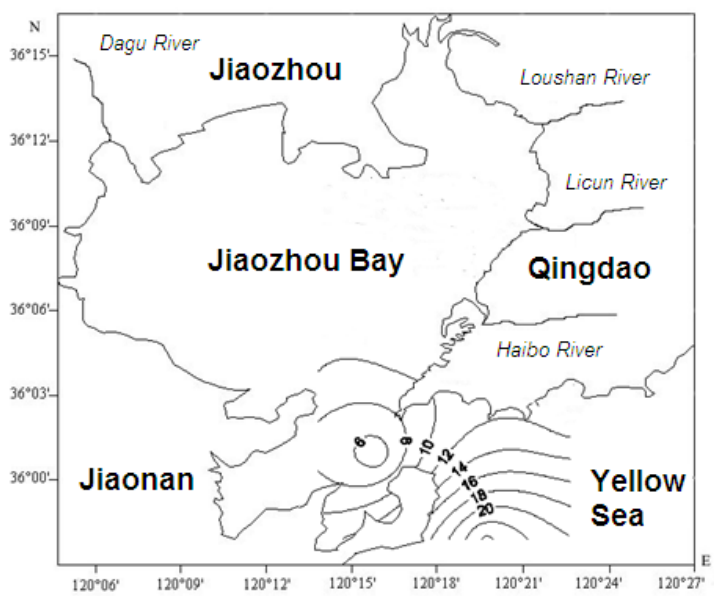

Fig. 4 Distributions of Zn in bottom waters in Jiaozhou Bay in October 1983/ $\mathrm{g} \mathrm{L}^{-1}$ 
The disjunction effect of marine bay mouth to Zn. In Jiaozhou Bay, the high contents of the substances in the bay were tending to be decreasing by means of water exchange [7]. However, how about the high contents of the substances outside the bay? As we known that $\mathrm{Zn}$ contents in different seasons were decreasing along with the flow direction of the marine current when were passing through the bay mouth. It could be considered that the sedimentation rates of $\mathrm{Zn}$ were low in the inner side of the bay mouth, yet were high in the outside of the bay mouth, respectively. We hold that in Jiaozhou Bay, the $\mathrm{Zn}$ contents in the marine current were decreasing when were passing through the bay mouth. The bay mouth of Jiaozhou Bay was just like the filter, isolator and sieve, which are able to filtrate, isolate and filtrate the substances from the bay to the outside of the bay, in spite of the flow rate of the marine current in the bay mouth was much higher than in other areas. That was the 'disjunction effect'. Furthermore, we believed that by means of the disjunction effect, no matter the substances were in the inner side or outside of the bay mouth in any marine bays, their contents would be decreasing once the waters were passing through the bay mouth. We called this phenomenon as 'Yang's phenomenon'.

The evidences of the disjunction effect of marine bay mouth to $\mathrm{Zn}$. The substances in the ocean were transporting along with the tide and current. The bay mouth of Jiaozhou Bay was able to prevent the high concentration substances from the outside of the bay to the bay, even if the flow rate of the marine current in the bay mouth was very high. Hence, there were low value regions in the inner side of the bay mouth and high value regions in the outside of the bay mouth (Table 3 ). $\mathrm{Zn}$ contents in the inner side of the bay mouth in May, September and October were 1.24-2.13 $\mu \mathrm{g} \mathrm{L}^{-1}$, 6.67-11.11 $\mu \mathrm{g} \mathrm{L}^{-1}$ and 4.72-11.25 $\mu \mathrm{g} \mathrm{L}^{-1}$, respectively, while in the outside of the bay mouth were 1.94-120.66 $\mu \mathrm{g} \mathrm{L}^{-1}, 14.31-17.78 \mu \mathrm{g} \mathrm{L}^{-1}$ and 11.00-24.44 $\mu \mathrm{g} \mathrm{L}^{-1}$, respectively (Table 3). In generally, $\mathrm{Zn}$ contents in May, September and October in the outside of the bay mouth could be considered as high, low and moderate, while in the inner side of the bay mouth were all low. These were the strong evidences of the disjunction effect of marine bay mouth to $\mathrm{Zn}$. The waters could be able to arrive at anywhere in the bay, yet the substances could not, due to the disjunction effect of the bay mouth.

Table $3 \mathrm{Zn}$ contents in the inner side and outside of the bay mouth in May, September and October in Jiaozhou Bay in 1983/ $\mu \mathrm{g} \mathrm{L}^{-1}$

\begin{tabular}{cccc}
\hline Region & May & September & October \\
\hline $\begin{array}{c}\text { Inner side of the bay } \\
\text { mouth }\end{array}$ & $1.24-2.13$ & $6.67-11.11$ & $4.72-11.25$ \\
Outside of the bay mouth & $1.94-120.66$ & $14.31-17.78$ & $11.00-24.44$ \\
\hline
\end{tabular}

\section{Conclusions}

$\mathrm{Zn}$ contents in bottom waters in May, September and October in the bay mouth of Jiaozhou Bay in 1983 were 1.24-120.66 $\mu \mathrm{g} \mathrm{L}^{-1}, 6.67-17.78 \mu \mathrm{g} \mathrm{L}^{-1}$ and 4.72-20.44 $\mu \mathrm{g} \mathrm{L}^{-1}$, respectively. The pollution levels were relative high in May yet were relative low in September and October. By means of the disjunction effect, no matter the substances were in the inner side or outside of the bay mouth in any marine bays, their contents would be decreasing once the waters were passing through the bay mouth. We called this phenomenon as 'Yang's phenomenon'. Finally, the disjunction effect of marine bay mouth was proved by the distribution of $\mathrm{Zn}$ in bottom waters in May, September and October in Jiaozhou Bay.

\section{Acknowledgement}

This research was sponsored by Doctoral Degree Construction Library of Guizhou Nationalities University, Education Ministry's New Century Excellent Talents Supporting Plan (NCET-12-0659), the China National Natural Science Foundation (31560107) and (31500394), Research Projects of 
Guizhou Nationalities University ([2014]02), Research Projects of Guizhou Province Ministry of Education (KY [2014] 266), Research Projects of Guizhou Province Ministry of Science and Technology (LH [2014] 7376).

\section{Reference}

[1] Yang DF, Zhu SX, Wang FY, et al.:Advanced Materials Research, Vol.1092-1093 (2015), p. 1013-1016.

[2] Yang DF, Chen ST, Li BL, et al.:Advances in intelligent systems research, Vol. (2015), p. 21-24.

[3] Yang DF, Chen Y, Gao ZH, et al.:Chinese Journal of Oceanology Limnology, Vol. 23(2005), p. $72-90$.

[4] Yang DF, Wang F, Gao ZH, et al.: Maine Science, Vol. 28(2004): 71-74. (in Chinese with English abstract)

[5] State Ocean Administration. The specification for marine monitoring: Beijing, Ocean Process, (1991).

[6] Yang DF, Wang FY, He HZ, et al.:Proceedings of the 2015 international symposium on computers and informatics, (2015), p. 2655-2660.

[7] Yang DF, Miao ZQ, Xu HZ, et al.: Marine Environmental Science, Vol. 32 (2013), p. 373-380. 